\title{
Тайны и загадки демографической статистики
}

Ю.С. ЕРШОВ, Институт экономики и организации промышленного производства СО РАН, Новосибирск. E-mail: eryus@mail.ru

Работа со статистическими показателями часто требует для их правильной интерпретации привлечение дополнительной информации. Некоторые данные можно считать либо производственным браком, либо свидетельством того, что произошло событие, близкое к практически невероятному. В статье приводятся примеры таких странных показателей и дается их авторская интерпретация. Ключевые слова: достоверность информации; интерпретация статистических показателей; миграционный прирост; аномалии половозрастной структуры населения; продолжительность жизни; возрастные коэффициенты смертности

Тайны и загадки - это то, что кажется непонятным, противоречащим логике, или даже просто ложным. Когда дело касается демографической статистики, во многих случаях это происходит из-за ограниченности информации, и привлечение дополнительной все объясняет. Нередко имеет место несоответствие между названием термина, его «бытовой» трактовкой и фактическим содержанием. Например, средняя продолжительность жизни или, в более развернутом варианте, ожидаемая продолжительность жизни при рождении. В 2017 г. значение этого показателя составило 72,7. Буквальная его трактовка как действительно «ожидаемой» продолжительности будет означать, что те, кто родился в 2017 г., в среднем проживут по 72,7 лет. Специалисты знают, что такая интерпретация неверна, и что на самом деле это не прогнозный, а отчетный показатель. Но если попытаться назвать его правильно - это показатель, рассчитываемый по следующей формуле... - формулировка получится очень длинной.

Другой пример - традиционное деление всего населения на городское и сельское. Если не вникать в детали, а просто смотреть на динамику городского и сельского населения, она либо покажется неправдоподобной, либо вы можете прийти

\footnotetext{
${ }^{*}$ Статья подготовлена в рамках выполнения работ по проекту XI.171.1.2 Исследование механизмов пространственной эволюции и моделирование развития пространственных систем.
} 
к неверным выводам. Вот одна из самых простых загадок нашей демографической статистики.

\section{Ренессанс российского села?}

В советский период сельское население России достаточно быстро сокращалось - к 1990 г. его численность снизилась до 38,9 млн чел. против 55,9 млн по итогам переписи 1959 г., соответственно уменьшилась и доля в общем населении - с 47,6\% до 26,4\%. В ходе рыночных реформ процесс пошел в противоположном направлении - к 1995 г. число сельских жителей увеличилось до 40,1 млн чел., а его доля превысила 27\%. Затем опять сокращение и численности и доли, но гораздо медленнее, чем в течение последних трех советских десятилетий: уровня 26,4\% сельское население вновь достигло лишь к 2010 г.

Правдива ли такая статистика? Тот, кто бывал неоднократно в сельской местности в конце 1990-х и даже в начале 2000-х, мог наблюдать удручающую картину - заколоченные дома, заброшенные деревни, полуразрушенные производственные помещения. А по статистике - реформы резко затормозили процесс урбанизации и отток населения из сельской местности.

Но если не ограничиваться лишь самой первой таблицей статистического сборника, а посмотреть еще и другие, несложно обнаружить главную причину «ренессанса»- численность городского и сельского населения может меняться не только в результате естественного движения и миграции, но и за счет смены статуса населенных пунктов. В советские времена на высокую динамику урбанизации оказывали факты преобразования сельских поселений в поселки городского типа. Часто просто потому, что село достаточно крупное и является районным центром. После начала рыночных реформ пошел обратный процесс - поселкам городского типа стали в массовом порядке возвращать статус сельских поселений. Некоторые субъекты Федерации ликвидировали эту категорию поселений полностью. После 1990 г. в результате таких преобразований более 2,4 млн бывших горожан стали сельскими жителями.

Краткие демографические термины часто могут вводить в заблуждение. Что такое сельское население? Сущностного определения нет, есть только формальное - это все население, проживающее за пределами границ населенных пунктов, которые 
официально считаются городами и поселками городского типа (из этого правила есть два исключения - Москва и Севастополь, в них есть не только сельское население, но и посевные площади, валовые сборы, поголовье скота). И значительная часть этого населения никакого отношения к селам и сельскому образу жизни не имеет. Это военнослужащие и гражданский персонал воинских частей, расположенных обычно за пределами городской черты; отбывающие наказание в тюрьмах и колониях-поселениях и персонал службы исполнения наказаний. В обоих случаях речь идет преимущественно о мужчинах, и по этой причине мужчины в составе «сельского населения» имеют численное преимущество до 40 и более лет, в городах они его теряют уже в 24 года (по состоянию на 01.01.2018). Есть еще и третья, растущая группа «сельского» населения - проживающие в индивидуальных, и не только индивидуальных, домах вблизи городов, но за пределами городской черты. Статистика тоже относит их к сельским жителям, хотя для них доступны все городские блага, и вся их жизнь связана с городом.

Игнорирование этой специфики реального наполнения термина может вызывать сомнения в достоверности некоторых статистических данных. Например, слишком малыми могут показаться различия в среднем возрасте или в средней продолжительности жизни городских и сельских жителей. Межрегиональные различия в возрастных коэффициентах смертности молодых «сельских» мужчин для отдельных регионов могут показаться очень низкими. Но это вполне логично объясняется - там, где относительно велика доля военнослужащих, возрастные коэффициенты смертности таких мужчин должны быть низкими. Просто потому, что в армию больных и инвалидов не берут, да и количество потенциальных внешних причин смерти (в результате аварии, в состоянии алкогольного опьянения и т.п.) намного меньше.

Или различия в уровне рождаемости. Традиционным и вполне логичным соотношением был повышенный уровень рождаемости в селах. И не потому, что к этому располагает сельская природа. Просто там нет такой веской причины отложить создание семьи и рождение детей, как необходимость сначала получить образование. И если женщина не смогла или не захотела поступать в вуз или техникум, то зачем затягивать создание семьи? И с квадратными метрами на селе проще - при необходимости 
можно утеплить веранду или сделать пристройку к дому, и двор индивидуальный есть. А в последние годы уровень рождаемости у сельского населения стал даже ниже, чем у городского. Почему - надо разбираться. Возможно, у «настоящего» сельского населения он по-прежнему остается выше, но близкий к нулю уровень рождаемости в воинских частях или «на зонах» портит статистику.

Предваряя последующие выводы, отметим, что большинство «странностей» перестают быть таковыми, если разобраться в проблеме подробнее. В отдельных случаях можно просто признать, что изредка «случиться может всякое». Но часть «странностей» кажутся таковыми, потому что при анализе динамических рядов игнорируются факты изменения методики расчета показателей. Вдруг выросла младенческая смертность. На самом деле дети умирать чаще не стали, а изменилось содержание показателя: к числу рожденных живыми стали относить и часть тех, кого ранее не относили. Или - в текущем десятилетии масштабы миграции стали вдвое большими, чем в предыдущем. Просто потому, что к мигрантам, попадающим в категорию постоянного населения, стали относить и часть тех, кого раньше не относили и т.д. Задним числом пересчитать всю ретроспективу по новой методике невозможно, информация, необходимая для этого, не сохранилась. Вот и получаются невольные «сенсации».

Но иногда встречаются и такие статистические казусы, объяснить которые можно лишь ошибками в получении и обработке.

\section{Коня на скаку остановит, в горящую избу войдет}

Так писал о русских женщинах поэт Н.А. Некрасов. Он перечислял и другие их достоинства, но эти два более всего показывают способность совершить подвиг. Речь идет, по-видимому, не просто о скачущем коне, а о неуправляемом. И для совершения такого подвига, равно как и для того, чтобы броситься в горящий дом, нужна сильная мотивация - например, спасение чьей-то жизни. И еще одна важная особенность таких подвигов - для их совершения нужны минуты или даже секунды.

Однако есть и другие подвиги российских женщин, которые великому поэту и присниться не могли, и для совершения которых нужны не минуты, и не часы, а годы. Откроем бюллетень Росстата «Естественное движение населения Российской Феде- 
рации». Начиная с 2012 г. в нем публикуются данные о возрасте и образовании матерей. Если верить этим данным, то в 2012 г. в России было 348 (!) юных матерей в возрасте менее 20 лет и уже имеющих законченное высшее образование. А сколько же тогда всего женщин-вундеркиндов, если талантливые и увлеченные учебой, как правило, не склонны к ранним бракам и деторождению? А одна женщина в этом же году и родила, и закончила вуз еще до достижения возраста 18 лет.

Можно ли верить такой статистике? Не хочется. По-видимому, в родильных домах информация об образовании матери записывалась со слов, а показать диплом или его копию никто не требовал. При некорректной или поспешной постановке вопроса легко можно перепутать или просто не различать категории «законченное высшее» и «незаконченное высшее». Кто-то, видимо, обратил внимание на огромное количество героинь и потребовал навести порядок в анкетировании матерей, и в 2014 г. статистика зафиксировала лишь одну юную маму с законченным высшим образованием. Далее их количество опять возросло, но уже не так сильно (в 2017 г. - 44 случая). Возможно, немного ослабили контроль.

Следующий пример иллюстрирует использование несуразного термина, к тому же никак не прокомментированного в методологических пояснениях Демографического ежегодника России.

\section{Когда в товарище согласья нет}

Многие статистические показатели Росстат приводит в нескольких своих изданиях. Так, например, информация о численности населения, рождаемости, смертности и миграции представлена и в Российском статистическом ежегоднике, и в Демографическом ежегоднике России и в других сборниках и бюллетенях. Как правило, эти данные совпадают. Небольшие различия можно обнаружить лишь в связи с тем, что в одних изданиях публикуются оперативные данные, в других - окончательные, которые могут измениться лишь по итогам очередной переписи населения. Но из этого правила есть одно интересное исключение.

Что такое «миграционный прирост населения России за счет передвижений внутри России»? Никаких разъяснений на этот счет в Демографическом ежегоднике нет. Буквальная трактов- 
ка - рождения или смерти в пути - здесь не проходит. Такие случаи, конечно, бывают, но не в таком количестве, а их регистрация осуществляется в конкретном населенном пункте - там и будет считаться родившимся или умершим тот, кто случайно родился или умер во время «передвижений».

Фрагмент информации о прибывших в Россию и выбывших из страны в 1991-1996 гг. (из двух источников)

\begin{tabular}{|l|c|c|c|c|c|c|c|}
\hline \multicolumn{1}{|c|}{ Показатель } & 1991 & 1992 & 1993 & 1994 & 1995 & 1996 \\
\hline & \multicolumn{5}{c|}{ Российский статистический ежегодник, 2017 г. } \\
\hline Прибывшие & 806016 & 1011313 & 979300 & 1191355 & 866857 & 647026 \\
\hline Выбывшие & 732217 & 704136 & 493119 & 345623 & 347338 & 291642 \\
\hline Миграционный прирост & 73799 & 307177 & 486181 & 845732 & 519519 & 355384 \\
\hline & \multicolumn{7}{|c|}{ Демографический ежегодник России, 2017 г. } \\
\hline Прибывшие & 692238 & 926020 & 923280 & 1191355 & 866857 & 647026 \\
\hline Выбывшие & 675497 & 673143 & 483028 & 345623 & 347338 & 291642 \\
\hline Миграционный прирост & 227371 & 386389 & 375838 & 877532 & 603198 & 443296 \\
\hline $\begin{array}{l}\text { В том числе за счет передвижений } \\
\text { внутри России }\end{array}$ & 210630 & 133512 & -64414 & 31800 & 83679 & 87912 \\
\hline $\begin{array}{l}\text { за счет обмена с зарубежными } \\
\text { странами }\end{array}$ & 16741 & 252877 & 440252 & 845732 & 519519 & 355384 \\
\hline
\end{tabular}

С 2005 г. эта категория населения, которая увеличивала население страны просто путем передвижений по ней, исчезает. Почему? Следуя формальной логике, остается предположить, что к этому времени учет миграционных потоков стал более полным, а то, что называлось «приростом за счет передвижений» - это просто «чистые ошибки и пропуска» (так называет величину расхождений ЦБ РФ между приходом и расходом денежных средств в платежном балансе страны, демонстрируя чистоту расчетов и отсутствие преднамеренной подгонки чисел). Зачем Росстат ввел вместо статистического расхождения такой несуразный термин, непонятно.

Остается объяснить небольшое искажение строки Н.А. Крылова в названии раздела. Слово «товарищ» написано в единственном числе не только потому, что оба справочника издает один и тот же Росстат. Председатель редакционной коллегии первого одновременно является и членом редколлегии второго. 


\section{Кавказские долгожители - миф или реальность?}

Это понятие появилось давно, и, возможно, тот, кто ввел его в обиход, подробно не изучал демографическую статистику, а просто встречал на Кавказе очень старых людей намного чаще, чем в других регионах страны. Но если сравнить данные Росстата о численности населения в самой пожилой категории - 100 лет и старше - например, по состоянию на начало 1991 г., то увидим прямое подтверждение кавказского феномена долгожительства тогда на территории современного Северо-Кавказского федерального округа проживали 3639 человек из этой возрастной категории. Это 31,5\% всех российских долгожителей, в то время как все население округа составляло лишь 5,1\% населения России. Еще более выразителен показатель мужского долгожительства на Северный Кавказ приходилось тогда 42,8\% всех российских мужчин старше 100 лет.

А теперь перенесемся в наши дни - данные о возрастной структуре населения показывают, что на начало 2018 г. число северокавказских долгожителей составляло всего 875 человек лишь 5,0\% от общей численности таких граждан по всей России, в то время как доля Северного Кавказа в населении страны повысилась до 6,7\%. Значительно меньше стало и лиц в возрасте 98-99 лет, в 1991 г. их было 1148, в 2018 г. - лишь 501. Что же случилось с северокавказскими долгожителями?

Версий ответа может быть несколько, и ни одна из них не доказуема. Изменились в худшую сторону условия жизни, в том числе доступность и качество медицинской помощи? Может быть, виной всему урбанизация? Первое исключается, второе тоже - сейчас процент горожан среди долгожителей - 83,2\%, и только на Москву приходится 30,7\% всех российских граждан старше 100 лет. Возможно, виной всему две «чеченские войны» и действия боевиков-террористов в регионах Северного Кавказа? Но гипотеза о том, что среди них было непропорционально много очень пожилых людей, представляется невероятной. Возможно, в силу каких-то более ранних исторических причин в возрастной пирамиде населения Северного Кавказа образовались провалы, в результате которых в возраст 100 лет и более стали вступать малочисленные группы населения? Статистика эту версию опровергает - если вернуться в 1991 г., то возрастная пирамида для населения старших возрастов здесь вполне нормальная, число 
90-летних составляло 6072 чел., 80-летних - 25851, 70-летних 36290, 60-летних - 84714 .

И, наконец, последняя версия - возможно, ранее не было такого большого числа долгожителей, как показывает статистика. Сто лет и старше в 1991 г. - это рожденные в 1890 г. и ранее. ЗАГСов тогда не было, и свидетельств о рождении не выдавали. Другие документы, в которых каким-то образом регистрировались факты рождения, в значительной части были утеряны в ходе революции и войн. Поэтому в очень многих случаях дата рождения человека устанавлась просто со слов. Однако если принять версию переоцененности численности долгожителей в прошлом, появляется другой вопрос - с какой целью люди завышали свой возраст, и почему масштабы этой переоцененности были особенно велики на Северном Кавказе?

У регионов Северного Кавказа есть и другие интересные демографические особенности. Одна из них относится к Республике Ингушетия.

\section{Феномен ингушских мальчиков}

Мальчиков, как правило, рождается больше, чем девочек. И хотя младенческая, детская и в зрелом возрасте смертность у мужчин выше, превосходство в числе рожденных позволяет им сохранять численный перевес в течение трех десятилетий и немного более. Для некоторых детских возрастных категорий в малых регионах могут быть кратковременные исключения из этого правила, вызванные либо фактом преобладания числа девочек среди новорожденных в отдельные годы, либо слишком малым численным перевесом мальчиков. И лишь Республика Ингушетия далеко не соответствует этой общей закономерности.

Если посмотреть на половозрастную структуру населения Ингушетии по состоянию на начало 2018 г., в глаза бросается очень странная особенность - начиная с возраста шести полных лет и далее численность мужчин меньше численности женщин весьма значительно. Так, в семилетнем возрасте мальчиков всего 46,4\%, в двенадцатилетнем $-45,8 \%$, в тринадцатилетнем даже $44,7 \%$. Если бы не было информации за предыдущие годы, можно было бы выдвинуть версии, близкие к фантастическим - либо на шестом году жизни у мальчиков на территории республики начинается какой-то мор, либо часть их в этом возрасте по какой-то причине 
вывозят в другие регионы. Короткое расследование показывает, что обе версии несостоятельны. Если посмотреть на половозрастную структуру населения по состоянию на начало 2012 г., то число мужчин оказывается меньше числа женщин во всех возрастных категориях. И объяснением могут быть два основных фактора по какой-то причине в течение многих лет подряд в числе родившихся доля мальчиков была либо меньше, либо ненамного больше половины, а высокие показатели младенческой смертности очень быстро приводили к тому, что уже через год в числе годовалых малышей мальчики оставались в меньшинстве. Почему-придумать невозможно, если бы так было всегда, можно было бы предположить какие-то особенности местного климата или физиологии ингушского населения. Но так было не всегда и так перестало быть после 2011 г. Более того, в последние годы природа как бы наверстывает упущенное - доля мальчиков среди родившихся в Ингушетии превышает 52\% (вместо обычных средних показателей 51,3-51,4\%). Поэтому единственное разумное объяснение феномена ингушских мальчиков - произошло событие, вероятность которого была положительной, но очень-очень малой.

Еще одну интересную особенность показывает демографическая статистика Чеченской Республики.

\section{Феномен чеченских мужчин}

Если зайти в Интернет и поинтересоваться обсуждением вопроса двоеженства, можно прочитать весьма убедительные доводы в пользу его легализации. В кратком изложении аргументация сторонников двоеженства следующая - федеральные законы не запрещают мужчинам сожительствовать с двумя и более женщинами, иметь от них детей и даже долго «жить на две семьи». Это не является ни уголовным, ни административным правонарушением, кроме случая, когда мужчина уклоняется от материальной поддержки детей, и то лишь при условии, что этого требует мать. Но это нечестно, какие-то дети имеют унизительный статус рожденных вне брака или даже прочерк в графе «отец» свидетельства о рождении. А мы хотим, чтобы все было честно, и обе матери имели одинаковый формальный статус. И Коран этого не запрещает. Логика абсолютно безупречна, и возразить по существу нечего. Кроме того, что законы не запрещают и женщинам иметь детей и близкие связи с двумя и более мужчинами, 
и не только последовательно, но и параллельно. Так что, исходя из этого, можно разрешить и двоемужество.

Если верить СМИ, против двоеженства не возражал и глава Чеченской Республики, приводя дополнительный аргумент в силу известных причин здесь особенно не хватает мужчин, и многие женщины вынуждены оставаться одинокими. Действительно, жертвами двух чеченских войн должны были быть в основном мужчины. Но наличная статистика не показывает таких ожидаемых последствий. Более того, по доле мужчин в общей численности населения республика в числе лидеров на начало 2018 г. - 49,3\% (в среднем по России - 46,4\%). Выше этот показатель только на Чукотке, на Камчатке и в Ямало-Ненецком АО. Но у последних повышенная доля мужчин вполне объяснима. А как объяснить столь высокую долю мужского населения в Чеченской Республике?

Первое, что приходит в голову - возможно, это потому, что на территории республики расположены крупные воинские части. Это повышает формальный показатель численности мужчин, их много, но эти военнослужащие не являются потенциальными женихами для чеченских женщин. Однако после анализа половозрастной структуры населения эта версия становится несостоятельной.

Можно выдвинуть еще одно предположение - в период чеченских войн против федеральных войск выступали преимущественно не постоянные жители республики, а наемники и фанатики, прибывшие сюда из других регионов и стран. Их гибель на статистику постоянного населения не должна была влиять.

И эта версия кажется неправдоподобной. Необходимо дальнейшее расследование - посмотрим, какова доля мужчин не только в целом, но и в отдельных возрастных категориях. По младенцам, детям и молодым категориям населения «все как у всех»- доля мужского населения не выше, чем в целом по России, доля граждан на третьем десятке даже ниже, а в старших возрастах доля мужчин сокращается намного медленнее. Так, в числе 60-летних в Чеченской Республике мужчин 46,3\% (против 42,9\% по России), в числе 70-летних - 41,5\% (против 36,7\%), в числе 80-летних - 34,9\% (против 28,0\%), в числе долгожителей (100 лет и более) - 40,3\% (против 27,0\%). И если посмотреть различия в возрастных коэффициентах смертности между 
мужчинами и женщинами, то здесь они для старших возрастов менее значительны, чем в целом по стране. В итоге в Чеченской Республике разрыв между показателями средней продолжительности жизни для женщин и мужчин составляет в последние годы лишь 5,5 лет по сравнению с разрывом в 10 лет для всей России. А в 1990 г. в Чечено-Ингушской АССР разрыв в этих показателях был таким же, как и в целом по РСФСР - 10 лет.

Итак, ответ на вопрос о том, почему так выросла доля мужчин в населении Чеченской Республики формально найден - вследствие сокращения разрыва между показателями продолжительности жизни у мужчин и женщин. Но этот ответ сразу вызывает другой вопрос - почему он здесь сократился? И не только здесь, но и в соседних республиках - особенно в Дагестане и Ингушетии. В 2017 г. по сравнению с 1990 г. продолжительность жизни мужчин в России увеличилась всего на 3,8 года, а в Дагестане на 7,0 лет, в Чеченской Республике - на 7,7, в Кабардино-Балкарии - на 6,2. А в христианской Северной Осетии - всего на 4,9. Очевидно, наиболее вероятный ответ на такой вопрос - это следствие возрождения или повышения статуса религиозных институтов, осуждающих многие человеческие пороки, в том числе и сокращающие продолжительность жизни. В окружении правоверных вынуждены менять свое поведение и атеисты.

И если мы коснулись проблемы продолжительности жизни, то хотелось бы найти хотя бы какой-то ответ на другой вопрос.

\section{Почему 10 лет, и почему не сокращается разрыв?}

Десятилетний разрыв в продолжительности жизни мужчин и женщин - был таким в начале 1990-х, таковым же остается и сейчас. Здесь мы впереди планеты всей. И если бы мы сильно опережали по этому показателю только исламские страны, все можно было бы объяснить - с одной стороны, позитивным влиянием на продолжительность жизни мужчин трезвого образа жизни, с другой - возможным негативным влиянием на продолжительность жизни женщин их подчиненного статуса в семье и обществе, измученностью ранними и многочисленными родами, тяжелой работой по обслуживанию большой семьи и т.п. Но мы сильно опережаем и другие страны, как развитые, так и не очень. В США этот разрыв менее пяти лет (оценка ВО3 
на 2015 г.), в Великобритании, Швеции, Норвегии - меньше четырех, в Исландии даже меньше трех.

Почему так велик разрыв? Объяснить это только тем, что наши мужчины много пьют и курят, было бы слишком просто и поэтому неправильно. Во-первых, есть страны, где душевое потребление алкоголя превышает наши показатели. Так, в 2014 г., по данным ОЭСР, нас опережали Венгрия, Словения, Польша, Германия, Ирландия, Чехия, Франция, Бельгия, но там нет такого большого разрыва в мужской и женской продолжительности жизни. Во-вторых, по масштабам употребления алкоголя и табака женщины сейчас стали гораздо ближе к мужчинам, чем это было в СССР. А разрыв не сокращается.

Сравнение по разным странам показателей продолжительности жизни обнаруживает очень интересную подробность. Таких, как мы, очень мало, и все они - страны постсоветского пространства. Это Эстония (разрыв в продолжительности жизни мужчин и женщин более 9 лет), Латвия (более 9 лет), Литва (11 лет), Белоруссия (более 11 лет), Украина (почти 10 лет), Молдавия (более 8 лет). Казахстан (9 лет). В других бывших союзных республиках этот разрыв меньше, но не дотягивает до уровня США и развитых стран Европы. А ведь с момента ликвидации СССР прошло уже более четверти века. Что это - какие-то очень долговременные последствия советского периода и советского строя? Возможно, ведь большинство населения постсоветских стран в той или иной степени захватило и советский период. Косвенно в пользу такого вывода свидетельствует еще один интересный факт. Он касается уже не разрыва в продолжительности жизни между мужчинами и женщинами, а продолжительности жизни всего населения.

В течение длительного времени в РСФСР продолжительность жизни вообще не росла-в 1961-1962 гг. она составляла 68,75 лет, в 1984-1985 гг. - 68,08. А ведь условия жизни, бесспорно, изменялись к лучшему. Постоянно повышался уровень благоустройства жилья, для все большей части населения становилась быстродоступной медицинская помощь, росли душевые показатели потребления продуктов питания, сильно сократилась младенческая смертность - с 36,6 в 1960 г. до 20,7 промилле в 1985 г.

Самой плачевной была динамика продолжительности жизни сельского населения, она снизилась с 68,6 до 66,3 лет. Этому факту можно дать логичное объяснение - здесь сравниваются 
не совсем сопоставимые группы населения. В советский период шел интенсивный процесс изменения статуса поселений-многие села становились поселками городского типа, и это были самые крупные села, часто районные центры, где уровень развития здравоохранения был гораздо выше, чем в глубинке.

Чем же можно объяснить отсутствие увеличения продолжительности жизни в течение столь длительного периода? В самых общих словах - долговременными последствиями войн ХХ века. Возможно, у большинства населения был подорван запас прочности, как войнами и горечью потерь, голодом и холодом, и впоследствии он все более исчерпывался по нарастающей, быстрее, чем это происходит для среднестатистического человека при увеличении его возраста.

Следующий интересный феномен напрямую связан с будущим старших поколений населения.

\section{«Смертельный вирус» пенсионного возраста?}

Росстат не публикует в общем доступе погодовые коэффициенты смертности, а лишь интервальные, по пятилетним группам населения. Но наличие возрастной структуры населения в погодовом разрезе позволяет установить динамику численности населения каждого конкретного года рождения. Если бы не было миграции, эта динамика позволяла бы определить не интервальные, а погодовые коэффициенты смертности (дожития).

Впрочем, для людей старших возрастов искажающее влияние миграции, а точнее, его сальдо, на коэффициенты изменения во времени численности населения того или иного года рождения минимально. Например, число умерших мужчин в возрасте 60-64 года почти на два порядка превышает значение положительного сальдо миграции для этой возрастной категории. Поэтому коэффициенты изменения численности должны быть очень близки к коэффициентам дожития, а исчисленные на их основе коэффициенты смертности почти соответствовать фактическим.

Чем старше среднестатистический человек, тем выше для него возрастной коэффициент смертности (исключение из этого правила-лишь самые юные, младенцы и малыши). Но нас интересует динамика этих коэффициентов, и особенно в предпенсионном и раннем пенсионном возрасте, с целью установить, как на них воздействует факт выхода человека на пенсию. Начнем с анализа 
самых последних данных о численности мужчин 1954-1959 гг. рождения на 01.01.2018 и на 01.01.2017. В течение 2017 г. мужчин 1959 г. рождения в России стало на 1,9417\% меньше, мужчин 1958 г. рождения - меньше на 2,1122\% , 1957-го - на 2,3108\%, 1956-го - на 2,6140\%, 1955-го - на 2,7810\%, 1954-го - на 3,0166\%. Если перейти к промилле, то для соответствующих возрастов это 19,$417 ; 21,122 ; 23,108 ; 26,140 ; 27,810 ; 30,166$. А теперь посмотрим, как растут коэффициенты смертности - сначала на 1,705, далее на 1,985, затем на 3,032 и. наконец, на 1,671 и на 2,356. Самый большой абсолютный прирост - для тех мужчин, которым в 2017 г. исполнилось 60 лет, т.е. для только что вступивших в пенсионный возраст.

Почему? Может быть, в голове постоянно пульсирует мысль о том, что ты уже «старик»-ведь пенсия называется «пенсией по старости». Сначала бьет сильно, а потом уже привыкаешь к этому статусу. Вряд ли надо искать какое-то более материалистическое объяснение. Всех ставших пенсионерами можно разбить на три группы. Одни продолжают работать (и даже на прежнем месте), и у них в 60 лет ничего не меняется, кроме того, что повышаются денежные доходы. Других уволили по причине достижения пенсионного возраста (хотя формулировка может быть иной или просто не продлили контракт) - для них это удар и снижение текущих доходов. Третьи ушли добровольно, но не могут сразу адаптироваться к своему новому положению некуда спешить, нечего делать и т.д. Вполне вероятно, что для последних двух групп первоначальные последствия наступления пенсионного возраста являются фактором, увеличивающим смертность в большей мере, чем просто от увеличения возраста еще на один год.

А как обстоят дела с увеличением смертности в окрестностях пенсионного возраста у женщин? Точно так же. Сами значения возрастных коэффициентов смертности у них традиционно меньше, чем у мужчин, но с увеличением возраста они растут. Для вступивших в пенсионный возраст в 2017 г. - на 1,24 промилле больше, чем для тех, кому исполнилось только 54 года (0,41 промилле). Для тех же, кому в 2017 г. исполнилось 56 лет - лишь на 0,256 промилле. И далее прирост этого коэффициента менее значимый, чем для новоиспеченных пенсионерок, лишь в возрастах 64 года и позже приросты становятся больше, чем для 55-летних. 
Так что вполне вероятно, что повышение пенсионного возраста станет фактором, уменьшающим возрастные коэффициенты смертности хотя бы в начале современного пенсионного возраста и увеличивающим среднюю продолжительность жизни. Время покажет. В 2017 г. разговоры о грядущем повышении пенсионного возраста еще не вышли на финишную прямую, а продолжительность жизни у мужчин уже выросла на целый год, уменьшилось абсолютное число умерших, несмотря на увеличение доли пожилого населения в общей численности, несмотря на санкции и застой в динамике показателей уровня жизни.

В заключение рассмотрим еще один интересный феномен.

\section{Феномен относительной «консервации» мужчин}

Сравнение возрастных коэффициентов смертности у мужчин и женщин обнаруживает следующую закономерность. Сначала относительный разрыв между этими показателями быстро растет не в пользу мужчин. Если для младенцев и детей в возрасте до пяти лет превышение составляет лишь 1,25 раза, в возрасте 5-9 лет уже 1,45, для категории 10-14 лет - 1,70, то в средних возрастных категориях мужская смертность превышает женскую в три раза и даже более (максимум в возрасте 20-24 - 3,5 раза), затем различия в возрастных коэффициентах смертности начинают быстро сокращаться. В возрастной категории 65-69 лет превышение составляет 2,49, в категории 70-74 - 2,12, в категории 78-79 - 1,77, в категории 80-84 - 1,38 (это результат сравнения среднегодовых показателей за 2013-2016 гг. В чем причина и что на первом месте - особенности физиологии или социальные факторы? Первые должны быть, иначе нельзя объяснить меньшую живучесть мальчиков. По социальным факторам они до определенного возраста не отличаются от девочек - еще не курят и не пьют, не дерутся, не гоняют на мотоциклах и автомобилях, не сидят в тюрьмах. По всей видимости, на относительно высокую смертность мужчин в средних возрастах в основном влияют уже эти факторы. Плюс более тяжелый и более опасный труд. В очень пожилом возрасте эти социальные факторы уже не вызывают высокую смертность мужчин - алкоголики и наркоманы до такого возраста просто не доживают, склонность к риску также резко падает, в том числе и из-за потери необходимых для этого физических данных. А сохраняются ли в старших возрастах 
какие-то различия в физиологии мужчин и женщин, из-за которых смертность у мужчин остается более высокой, или сказываются потери в здоровье во время «бурной молодости»- на этот вопрос демографическая статистика ответа не дает. Возможно, что на сокращение различий в смертности по мере увеличения возраста какое-то влияние оказывают факторы потери или приобретения каких-то свойств организмами мужчин или женщин, или и тех и других.

Самый странный и никак не объяснимый факт «относительной консервации» - это феномен мужчин, рожденных в 1900 г. Все его носители уже, по-видимому, умерли, и он имеет только историческую ценность. Если посмотреть на показатель доли мужчин в общей численности населения по состоянию на начало 2000 г., то обнаруживается, что у рожденных в 1900 г. доля мужчин составляет 46,4\%, в более старших возрастах (100 лет и более) лишь 19,1\%, для рожденных в 1901, 1902, 1903 гг. - соответственно $11,9 \%, 15,4 \%$ и $15,8 \%$. Почему так много сохранилось мужчин именно этого и только этого года рождения?

В 1990 г. все было, как обычно, доля мужчин в составе населения 1900 г. рождения составляла всего 15,2\%. Примерно такой же была их доля и в других близких возрастных категориях. Общее количество мужчин 1900 г. рождения составляло 13452 чел., женщин - 75311 чел. К 2000 г. соотношение составляло уже 461 против 533 , т.е. число мужчин сократилось в 29 раз, а женщин - в 141 раз. Смертность мужчин 1900 г. рождения в последнем десятилетии $\mathrm{XX}$ в. оказалась заметно меньше, чем у их ровесниц-женщин. Но эту загадку разгадать, по-видимому, невозможно.

\section{Summary}

Ershov Yu.S., Institute of Economics and Industrial Engineering, SB RAS, Novosibirsk

Secrets and Mysteries of Demographic Statistics

Working with statistical indicators often requires additional information to be understood and interpreted correctly. Some data can be considered either a manufacturing defect, or evidence that there was an event close to almost incredible. The article gives examples of such strange indicators and their author's interpretation.

Reliability of information; interpretation of statistical indicators; migration growth; anomalies of the sex and age structure of the population; life expectancy; age-specific mortality rates 